\title{
How Betrayal Affects Emotions and Subsequent Trust
}

\author{
Wing Shing Lee ${ }^{1}$ and Marcus Selart ${ }^{2, *}$ \\ ${ }^{1} I$-Shou University, Department of International Business Administration, Office No 1, Sec. 1, Syucheng Rd, Dashu \\ District, Kaohsiang City 84001, Taiwan; ${ }^{2}$ Norwegian School of Economics, Department of Strategy and Management, \\ Helleveien 30, NO 5045 Bergen, Norway
}

\begin{abstract}
This article investigates the impact of different emotions on trust decisions taking into account the experience of betrayal. Thus, an experiment was created that included one betrayal group and one control group. Participants in the betrayal group experienced more intense feelings governed by negative emotions than participants in the control group did. Moreover, participants in the betrayal group significantly lowered their trust of another stranger. On the other hand, we found some evidence that neuroticism exaggerated the relationship between experienced betrayal and subsequent trust.
\end{abstract}

Keywords: Betrayal, emotions, trust, decision making, neuroticism.

\section{INTRODUCTION}

Trust is an important issue in organizations since it has been observed to be connected with many positive processes and outcomes. Gargiulo and Ertug [1] summarized the benefits of trust in an organization under three broad headings. First, trust can reduce the cost of monitoring and thus the number of safeguards. Second, it can reinforce commitment in a relationship. Third, it can lead to more open communication and to a richer exchange of resources among people. Although these benefits from trust are appealing, it is sometimes not easy for one person to trust another because of the vulnerability involved. Mayer, Davis, and Schoorman [2] have defined trust as a person's willingness to be vulnerable to the actions of another party based on the expectation that such a party will respond according to the former's anticipation. In other words, trusting another person might open the possibility of being exploited by the latter party. Reduction in the number of safeguards might invite intrusions and over-commitment in a relationship that in turn may lead to groupthink. Also, a richer exhange of resources might give rise to the misappropriation of sensitive information. Therefore, it is not unusual that people may have difficulty in striking a balance between trust and distrust.

This struggle may be more intense when one faces a stranger. This is because there is no track record concerning the target's trustworthiness on which a person can rely to form his or her judgment. In this paper we attempt to explore that emotion plays a part in an individual's trust in a stranger. More specifically, we argue that an experience of betrayal, which is likely to generate negative emotions, may significantly affect an individual's subsequent trust in another stranger. Such contagious effect has rarely been investigated [3], but is important in the sense that it creates

*Address correspondence to this author at the Norwegian School of Economics, Department of Strategy and Management, Helleveien 30, NO 5045 Bergen, Norway; Tel: +47 55959695;

E-mail: Marcus.Selart@nhh.no an obstacle for future trust-building. Nonetheless, we also suggest that a person's personality with regard to emotions can make a difference in how an experience of betrayal impacts on one's subsequent trust in a stranger.

\section{Emotions and Initial Trust}

There is evidence showing that a person's emotional state is likely to influence his or her judgment relating to trust [4]. Forgas and East [5] revealed that a person's suspicion of a stranger is affected by the mood he or she experiences. When asked to judge whether a stranger had committed a theft and then denied the incident, sad participants were more likely to make guilt judgments than neutral and happy ones were. Dunn and Schweitzer [6] found that a person's emotional state can affect his or her trust in a stranger. They recruited participants at a railway station and asked them to undergo an emotion-induction exercise which induced anger, sadness, or happiness by describing a past incident. Then the participants were asked to rate the trustworthiness of a previously identified unfamiliar co-worker. The results showed that participants in the happy condition were more trusting than those in the sad and angry conditions.

\section{Betrayal and Negative Emotions}

The studies above have demonstrated that moods and emotions aroused from unrelated events affect a person's trust in a stranger. Thus, we propose that feelings aroused from a trust-related event - a betrayal - may have a striking effect on an individual's trust in a stranger. We adopt [7] Elangovan and Shapiro's definition of betrayal, which describes the phenomenon as a violation of pivotal expectations of a trustor. Lazare [8] provided insights into the feelings he experienced once when he was betrayed:

"Two friends betrayed my trust over an important matter. Their lying about it only compounded my hurt. For weeks after this discovery, I was distraught and distracted from my daily activities... I began to question both my trusting approach to relationships and my overall ability to judge people" (p.16). 
From the description above, two consequences arising from the incident of betrayal can be identified. First, there was an emotional impact: the author felt hurt and distraught. Second, he questioned his trusting approach and ability to judge people. This experience is akin to a traumatic event, although to a lesser extent. The fact that betrayal can cause negative emotions has been reported in a number of studies. First, a violation of a psychological contract can be viewed as one form of betrayal because it comprises both the element of trust and the expectation that another party will fulfil his or her obligations [7, 9, 10]. Robinson and Morrison [11] have discovered that when a person sees that a breach of psychological contract is purposefully done by another party under unfair conditions, he or she will experience strong feelings of violation. Second, Koehler and Gershoff [12] discovered that people reported intense negative feelings toward the manufacturer of a safety product that caused the harm from which it was claimed to protect them. Other experimental studies have also revealed that betrayal is linked to negative emotions $[13,14]$.

Feelings aroused from betrayal normally involve a number of negative emotions. First, when we are betrayed, most of us may feel disappointed or upset because the other party failed to meet our expectations [15]. Second, anger is also aroused because of the disappointment due to the unfairness of the act [16]. Third, a person may also encounter shame when betrayed because he or she thinks that his or her trust has been exploited [15, 17-19]. Therefore, our first hypothesis may be stated as follows:

H1: An experience of betrayal will cause feelings of disappointment, anger and shame.

\section{Betrayal and Subsequent Trust in Other Strangers}

As recounted by Lazare [8], a betrayal incident may lead an individual to question one's trusting approach. This is conceivable because people in crisis may sometimes challenge their basic values and beliefs [20]. There has been evidence suggesting that once a trust is violated, it is very difficult for a person to restore it to the level that existed before the violation took place $[13,14,21]$. Many of these studies investigated the effect of betrayal on subsequent trust of the same person. Nonetheless, we argue that the negative effect of betrayal on subsequent trust will also apply to other unrelated persons for two reasons. First, it is important to note that painful experience has been linked to counterfactual thoughts [22]. Such thoughts imply that a betrayed person may think that he or she would not have been in such a dire situation if only he or she had not been overly trusting. Second, the effect on subsequent trust is partly due to the emotions aroused by the betrayal, as well as the affective personality of an individuals. For example, selfdestructive individuals (characterized by low positive affect and high negative affect) and high affective individuals (characterized by high positve affect and high negative affect) are more vulnerable to trauma and negative life events [23].

It has been recognized that the emotion system serves as an important motivational system [24]. Emotions arouse, sustain, and direct human actions [25] and shift a person's attention to critical features of his or her environment [26,
27]. For example, dissatisfaction and disappointment inform a person that the maintenance of the current behavior or decision is not justified [28].

Empirical evidence has shown that negative emotions have an impact on decisions and judgments. Luce [29] reported that when a person is overwhelmed by negative emotions, he or she tends to refrain from making decisions. In the case of betrayal, this means that a person will defer the decision to trust another person whenever possible. Forgas and East [5] have found that those who were inflicted with a negative mood were more inclined to judge a target person as guilty of an offense. This implies that a negative affective state may arouse suspicion. Therefore, our second hypothesis states the following:

H2: An experience of betrayal will have an adverse effect a person's subsequent trust in a stranger.

\section{Individual Differences in Self-Regulation}

However, while we postulate that an experience of betrayal in general will negatively affect a person's subsequent trust in strangers, we still argue that there may exist individual differences in the reactions to betrayal. Parrot and Spackman [30] have contended that a person's emotional state at the time of retrieving can redefine an event. People who are deficient in regulating emotions or who are vulnerable to negative emotions are less likely than others to maintain the same level of trust in strangers. Thus, we discuss neuroticism can moderate the relationship between an experience of betrayal and subsequent trust in strangers.

\section{Neuroticism}

Neuroticism is one of the five domains in the Big-Five Personality Model and one of the three personality factors in Eysenck's trait theory [31] and normally is associated with the inability to handle emotions. Neuroticism is sometimes termed as emotional instability [32,33]. People who are high in neuroticism are normally regarded as moody, touchy, irritable, anxious, unstable, pessimistic, and complaining [34]. They are constantly in a tense state while those who are low in neuroticism are comparatively more relaxed [31]. Previous studies have reported that neuroticism is negatively correlated with emotional intelligence [35-37].

People high in neuroticism are less likely to believe that their emotions can be changed and more likely to believe that their own emotions are too strong to be controlled [38, 39]. They react more strongly to negative stimuli [37] and are particularly vulnerable to emotional change induced by events [40]. They also tend to adopt problematic coping strategies such as wishful thinking, withdrawal and emotionfocused coping [40, 41]. Moreover, people high in neuroticism have less tolerance for negative situations [42]. As a result, they are less likely to stick with the same course of action that generates negative emotions. In terms of betrayal and trust, we predict that people high in neuroticism will exaggerate the implication of a betrayal experience and will be more likely to switch to a more conservative approach to strangers. Therefore, our final hypothesis states the following: 
H3: Neuroticism will further damage one's subsequent trust in strangers in case of betrayal.

\section{METHOD}

\section{Participants}

Eighty-three business school students from the Norwegian School of Economics and Business Administration were recruited as participants. They were provided with the role of trustor in two different experimental conditions. 38.6 percent of the participants were female and 61.4 percent were male. Their average age was 23.0 years $(S D=2.56)$. Forty participants were included in the betrayal group and the other forty-three were included in the control group.

\section{Materials}

\section{Trust Game}

The trust game used [43, 44] implied that a trustor had 40 kroner (about 7 US dollars) on hand. Whatever amount the trustor decided to give to the trustee, the amount would be multiplied by four. The trustee, on the other hand, could decide to choose whether he or she would give half of the multiplied amount back to the trustor, or simply take the whole multiplied amount for himself/herself.

In the trust game, the rational choice for the trustee is to take the whole multiplied amount for himself/herself, as long as he or she is maximizing the monetary payoff. Knowing the rational choice of the trustee, the rational choice for the trustor will be to keep the entire original amount and give the trustee nothing. However, trust arises if the trustor is willing to give any amount greater than zero.

\section{Measures of Trust - Amount Sent and Trust Rating}

Both a behavioral measure and a survey measure of trust were used in connection with each of the two games. The behavioral measure, which has been used in previous studies $[43,45]$, was set to be the amount sent by the participants in the trust game. We then devised another survey measure which asked the participants to make a rating based on the following question: "I really trusted her to share half of the amount with me" using a 7-point Likert-type scale (from strongly disagree to strongly agree). The standardized coefficient alphas for these two measures of trust were .73 in game 1 and .81 in game 2 , respectively.

\section{Negative Emotions}

Three negative emotions - anger, shame, and disappointment - were measured using a 5-point scale based on the PANAS scale [46]. The scale included the attributes "very slightly or not at all", "a little", "moderately", "quite a bit", and "extremely". Only three negative emotions were chosen because these were closely related to the experience of betrayal. Anger is related to the unfairness of the situation [16]. Shame arise because one is being exploited [17]. Disappointment is due to the other party's failure to meet one's expectations [15]. In addition to individual emotions, we also combined the three emotions (anger, shame and disappointment) into a measure of averaged negative emotions. The coefficient alpha for this averaged measure for our sample was .76

\section{Neuroticism}

We adopted the BFI-44 in order to measure the neuroticism of participants which was reprinted from [32]. We extracted nine items that are related to mood or emotions as the measurement of neuroticism by using a 5-point Likerttype scale (from strongly disagree to strongly agree). Sample items include: "I see myself as someone who is depressed, blue", "I see myself as someone who is relaxed, handles stress well"(reverse score), and "I see myself as someone who worries a lot". The coefficient alpha for our sample was found to be .72 .

\section{Manipulation Check}

The manipulation check consisted of a single item measure. Participants were asked the following question: "I felt betrayed by the person in the game" using a 7-point Likert-type scale (from strongly disagree to strongly agree).

\section{Procedure}

\section{Pre-experiment Preparation}

Ten students, who were not part of the 83 participants, were asked to play the role of the trustee in the trust game. Each of them was told that he or she was going to play against a trustor. In the trust game, they could choose to either share half of the multiplied amount with the trustor or to take it all for themselves. Before they made their decisions, they were required to indicate that they wished to share the amount and this was recorded by a video camera. However, they were allowed to change their decisions afterwards and put the final decisions in writing. The whole process was videotaped. We explained the purpose of using the tapes and obtained the ten students' consent. The students were informed that the clips and all related materials would be erased after completion of the experiment. These video clips were then presented to another eight students. These students were required to rate the trustworthiness of the trustees without knowing the latter's final decisions. Based on their judgments, we chose two video clips that had the same rating. In one video-clip the trustee took the whole amount for herself and in the other the trustee shared it. Both trustees were female. In the experiment, only photos extracted from the video-clips were used.

Two days before the experiment, the eighty-three participants who would assume the role of trustor were first asked to fill in an online questionnaire for the assessment of their neuroticism.

\section{Experiment}

The participants were initially introduced to how to play the trust game. They were given two trial games so that they were familiar with the rules. After the trial games, participants were randomly assigned to the betrayal group or 
the control group by the computer program, based on the time each participant completed the trial games. The first completed participant was assigned to the betrayal group and the second one to the control group and so on. However, participants were not informed about the group to which they were assigned. Eventually, forty participants were assigned to the betrayal group and forty-three participants to the control group. Two participants did not complete the games.

\section{Betrayal Group}

Participants in the betrayal group were first presented with a photo of the first trustee. In the photo this person was about to write down whether she would be willing to share half of the multiplied amounts. In the description the participants were told that the person in the photo agreed to share half of the multiplied amount with them. They were asked to decide on the amount (Kr. 0; Kr.10; Kr.20; Kr.30; Kr.40) they would give her. They were also asked to rate her trustworthiness. Next, the photo that displayed the answer actually written down by the trustee was shown to them. It stipulated that she took the whole amount for herself. The participants then proceeded to play the second trust game. Again they went through the same procedure as described in the first game except that this time the trustee's answer indicated that she shared the amount.

\section{Control Group}

In the control group, the same procedure was applied as was done in the betrayal group except that the answer of the first game was not shown to the participants before they played the second game. In other words, participants did not know the answer of the first trustee when they played against the second trustee. All the measures were the same.

For both groups, other information such as age and gender was collected at the end.

\section{Debriefing}

When participants had completed the experiment, they were asked to complete a "Post-experimental questionnaire", asking them, among other questions, about the emotions they experienced at the time just before they started the second game. We did not ask before they started it, because prematurely calling attention to their emotions might have interfered with the emotional effects [5]. They were also asked to fill in the manipulation-check question. When all these procedures were completed, the purpose of the experiment was explained. The participants were given the maximum pay-offs no matter how well they actually performed in the games. This was to ensure that no one would suffer any loss because of the trustees' decisions. Alternatively, they could waive the amount in return for an opportunity to take part in a lucky draw for a mini-laptop.

\section{RESULTS}

\section{Manipulation Check}

First, we conducted an independent-samples t-test on the mean scores of feeling of betrayal between the betrayal group and the control group. Participants in the betrayal group experienced a significantly stronger feeling of betrayal $(M=5.38, S D=1.48)$ than those in the control group $(M=$ $2.60, S D=1.20 ; t(81)=9.61, p<.001)$. The results confirmed that our manipulation successfully produced a sense of betrayal in the betrayal group.

\section{Hypotheses}

Hypothesis 1 stated that an experience of betrayal would be associated with negative emotions. An independentsamples t-test was conducted to compare the average negative emotions experienced by the two groups. There was a significant difference in the scores for the betrayal group $(M=2.17, S D=.83)$ and the control group $(M=1.29, S D=$ $.58 ; t(69)=-5.57, p<.001)$. In other words, the participants in the betrayal group experienced more negative emotions on average than the participants in the control group did. Therefore, Hypothesis 1 was supported.

Hypotheses 2 proposed that an experience of betrayal would lower a person's subsequent trust in a stranger. A mixed ANOVA was conducted with the amount sent (the behavioral measure of trust) as the dependent variable and group belonging (betrayal, control; between-subject factor) and the attempt order of the trust game (first attempt, second attempt; within-subject factor) as the independent variables. The impact of group on the amount sent was found to be significant, Wilks Lambda $=.95, F(1,81)=4.08, p<.05$. The mean amount sent in the betrayal group dropped from $33.50(S D=8.93)$ in the first attempt to $28.00(S D=13.44)$ in the second attempt, whereas in the control group it dropped from only $31.40(S D=11.46)$ to $29.77(S D=$ 11.85). Another mixed ANOVA with the trust-rating (the survey measure of trust) as the dependent variable was also conducted. We discovered that the impact of group on trust rating was also significant, Wilks Lambda $=.92, F(1,81)=$ $6.85, p<.05$. The mean trust rating in the betrayal group dropped from $5.27(S D=1.06)$ in the first attempt to 4.70 $(S D=1.09)$ in the second attempt, whereas in the control group it dropped from only $5.00(S D=1.59)$ to $4.93(S D=$ 1.47). Hypothesis 2 was thus supported.

Hypothesis 3 postulated that individuals who scored high in neuroticism would further lower their subsequent trust in other strangers because of the betrayal incident. A mixed ANOVA was performed to investigate whether neuroticism (continuous) moderated the impact of the group (betrayal, control) on the trust decisions. We found that neuroticism (continuous) significantly moderated the impact of group (betrayal, control; between-subject factor) on the trust ratings in the two attempts (first attempt, second attempt; withinsubject factor). Wilks Lambda $=.89, F(2,77)=4.57, p<$ .05 . However, it did not moderate the impact of group on the amount sent, Wilks Lambda $=.95, F(2,77)=1.96, p=.15$. Fig. (1). depicts the change in trust rating in each group (betrayal, control) across three categories of neuroticism (high, middle, and low). It shows that betrayal had a greater impact on trust change for people with high neuroticism than for those with medium or low neuroticism. Hypothesis 3 was thus partially supported.

Overall, our results showed that participants in the betrayal group experienced significantly more negative emotions. They were also more likely to change their 


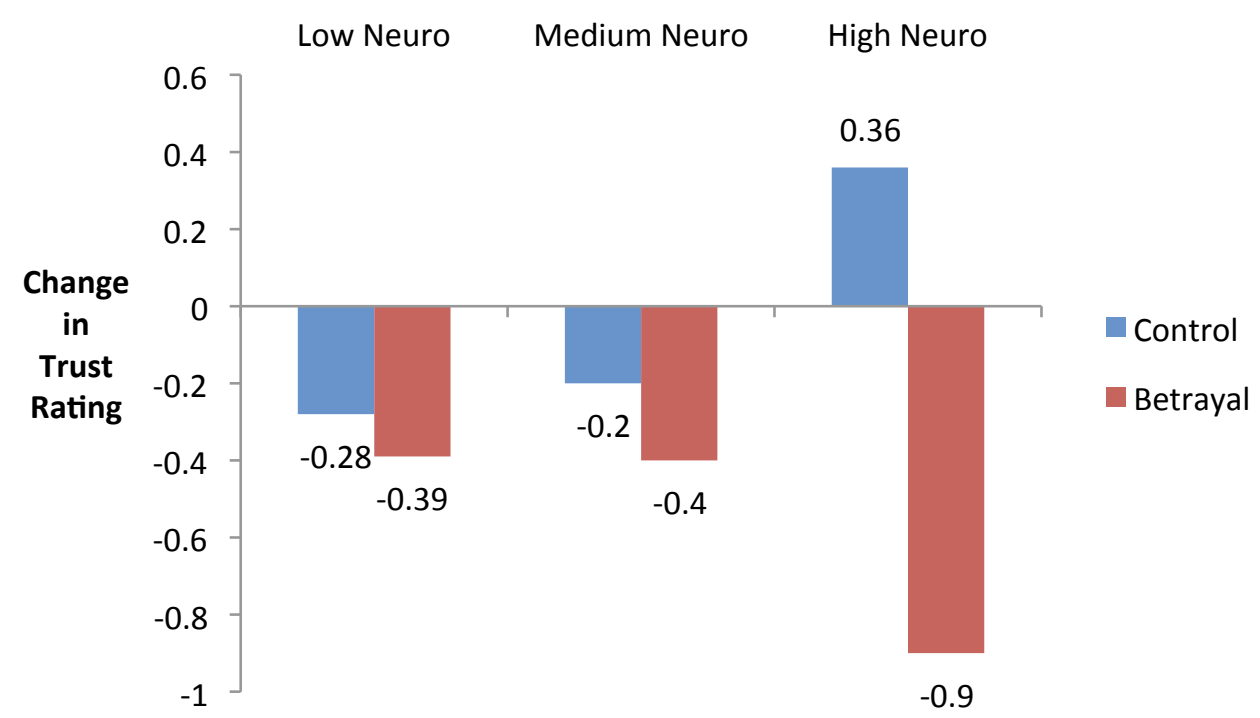

Fig. (1). The impact of neuroticism on the change in trust-rating across two groups.

subsequent trust in strangers. Neuroticism tended to exaggerate the effect of betrayal on subsequent trust, but only limited to trust rating.

\section{DISCUSSION}

Our results demonstrated that an experience of betrayal is associated with negative emotions such as anger, disappointment and shame. This confirms the results of a previous study, which indicated that betrayal gives rise to negative emotions [12]. On the other hand, the results also provided empirical evidence to support the claims that an incident of betrayal by a stranger will affect a person's willingness to trust another stranger [3, 47]. In addition, we found some support that not all individuals adjust their trust decisions in the same way in the event of a betrayal. Some partial evidence showed that individual's personality with regard to emotions has an impact on the relationship between betrayal and the change in subsequent trust. Our results showed that those who scored high in neuroticism tended to be more affected by the betrayal experience.

Nonetheless, the results concerning individual differences turned out to be more complicated than we had expected. The hypothesis relating to neuroticism was significant only with regard to the survey measure of trust, but not with regard to the behavioral measure of trust. To a certain extent, the difference in the results between the survey measure of trust and the behavorial measure was not surprising since similar differences have been found in a couple of empirical studies [48, 49]. The explanation of our results could be that the behavioral measure of trust included not only the trust motive but also other motives tied to, for instance, investments [13, 49]. It is thus possible that some participants rated the target person as trustworthy but decided to pay a lesser amount to her because of the fear of loss.

The above results imply that inside experiences of betrayal there exists an emotional component that might alter one's subsequent trust decisions. It seems that depending on whether one is active or passive towards emotions, there could be an impact on how a betrayal affects one's subseqent trust. An alternative explanation of the results could be that something more fundamental is at work: the implicit theories of emotions. Tamir, John, Srivastava, and Gross [50] argued that individuals are different in their beliefs about emotions. Some view emotions as fixed and thus have little incentives to try to modify them. Others view emotions as malleable and believe that they possess the ability to control them. Individuals who are high in neuroticism are characterized by their deficiency in negative mood repair [37], and therefore are more likely to view emotions as fixed and not modifiable. A previous study has found that people who are high in neuroticism are more likely to report that their emotions cannot be changed [38].

\section{Limitations and Future Research}

Nevertheless, there may be other reasons for the change in subsequent trust. First, the incident of betrayal may make the possibility of betrayal salient. In other words, some people may start to realize the logic of the trust game thoroughly after that the betrayal takes place. The trust game was designed in such a way that if the trustee tried to maximize his or her return, nothing should be returned to the trustor. Following this logic, the trustor's rational decision should be to retain all the possessed amounts. The heightened alertness due to this was thought to lead people to change their attitude toward the game and be more conservative in making another trust decision.

On the other hand, some people may tend to overgeneralize the trustworthiness of other people based on the first incident. Based on the betrayal experience, some may think that this is people in general's typical response when they are in the position of a trustee in the trust game. These participants are not assessing the logic of the game. Rather, they try to generalize from the betrayal incident to people in general's behavioral response in such a game. More studies are needed to investigate these other possibilities. 
Future studies may be needed to determine the role of emotional intelligence (EI) in the relationship between betrayal and subsequent recovery. Emotional intelligence was found to be negatively related to irrationality [51], and good at regulation of emotions [52]. We propose those who score high in EI may recover from a betrayal faster than those who score low. On the other hand, it may also be fruitful to investigate whether the implicit theories of emotion function as we have proposed when one faces betrayal. Furthermore, studies concerning affective personality and response to a betrayal should be carried out. This is based on the fact that affective personality has a significant effect on posttraumatic growth [23].

\section{CONCLUSION}

This article shows that negative emotions accompany a betrayal. It also shows that an incident of betrayal may substantially lower a person's subsequent trust in other strangers. In addition, our results show some signs that individuals' neuroticism tendency may further damage one's subsequent trust in strangers, although it is only partially supported. Overall, this study has provided some evidence that negative emotions accompanied by a betrayal incident, as well as an individual's emotional personality, play a substantial part in affecting an individual's subsequent trust in strangers.

\section{CONFLICT OF INTEREST}

The authors confirm that this article content has no conflict of interest.

\section{ACKNOWLEDGEMENTS}

Declared none.

\section{REFERENCES}

[1] Gargiulo M, Ertug G. The dark side of trust. In Bachmann R, Zaheer A, Ed. Handbook of trust research. Massachusetts: Edward Elgar Publishing 2006; pp. 165-86.

[2] Mayer RC, Davis JH. An integrative model of organizational trust. Acad Manage Rev 1995; 20: 709-34.

[3] Bohnet I, Zeckhauser R. Trust, risk and betrayal. J Econ Behav Organ 2004; 55: 467-84.

[4] Lee WS, Selart M. The impact of emotions on trust decisions. In: Moore KO, Gonzales NP, Eds. Handbook on psychology of decision making. hauppage, NY: Nova Science Publishers 2011; pp. 1-16.

[5] Forgas JP, East R. On being happy and gullible: Mood effects on skepticism and the detection of deception. J Exp Soc Psychol 2008; 44: $1362-67$

[6] Dunn JR, Schweitzer ME. Feeling and believing: the influence of emotion on trust. J Person Soc Psychol 2005; 88: 736-48.

[7] Elangovan AR, Shapiro DL. Betrayal of trust in organizations. Acad Manage Rev 1998; 23: 547-66.

[8] Lazare A. On apology. New York: Oxford University Press 2004.

[9] Rousseau DM. Psychological and implied contracts in organizations. Employee Resp Rights J 1989; 2: 121-39.

[10] Robinson SL. Trust and breach of the psychological contract. Admin Sci Quart 1996; 41: 574-99.

[11] Robinson SL, Morrison EW. The development of psychological contract breach and violation: a longitudinal study. J Organ Behav 2000; 21: 525-46.

[12] Koehler JJ, Gershoff AD. Betrayal aversion: when agents of protection become agents of harm. Organ Behav Hum Decis Process 2003; 90: 244-61.
[13] Schweitzer ME, Hershey JC. Promises and lies: restoring violated trust. Organ Behav Hum Decis Process 2006; 101: 1-19.

[14] Lount RB, Zhong C-B. Getting off on the wrong foot: the timing of a breach and the restoration to trust. Pers Soc Psychol Bull 2008; 34: 1601-11.

[15] Robinson SL, Dirks KT. Untangling the knot of trust. In: Kramer RM, Cook KS, Eds. Trust and distrust in organizations: dilemmas and approaches. New York: Russell Sage Foundation 2004; pp. 327-41.

[16] Ekman P. Emotions Revealed. New York: Henry Holt and Company 2007.

[17] Piper F, Monin N. Beneath the masks: A critical incident focus on the emotions experienced in the worker/supervisor relationship. In: Zerbe WJ, Ashkanasy NM, Hartel CEJ, Eds. Research on emotion in organizations. San Diego: JAI Press 2006; vol. 2, pp. 81-106.

[18] Vohs KD, Baumeister RF. Feeling duped: emotional, motivational, and cognitive aspects of being exploited by others. Rev Gen Psychol 2007; 11: 127-41.

[19] Lee WS, Selart M. The influence of emotions on trust in ethical decision making. Prob Perspect Manage 2014; 12: 571-8.

[20] Park CL. Fenster JR. Stress-related growth: predictors of occurrence and correlates with psychological adjustment. J Soc Clin Psychol 2004; 23(2): 195-215.

[21] Bottom WP, Gibson K. When talk is not cheap: Substantive penance and expressions of intent in rebuilding cooperation. Organ Sci 2002; 13(5): 497-513.

[22] Miller DT, Taylor BR. Counterfactual thought, regret, and superstitution: how to avoid kicking yourself. In Gilovich T, Griffin D, Eds. Heuristics and Biases. New York: Cambridge University Press 2002; pp. 367-78.

[23] Norlander T, Schedvin HV. Thriving as a function of affective personality: Relation to personality factors, coping strategies and stress. Anxiety Stress Copin 2005; 18(2): 105-16.

[24] Smith CA, Kirby LD. Affect and cognitive appraisal processes. In: Forgas JP, Ed. Handbook of affect and social cognition. New Jersey: Lawrence Erlbaum Associates 2001; pp. 75-94.

[25] Salovey P, Bedell BT. Current directions in emotional intelligence research. In: Lewis M, Haviland-Jones JM, Eds. Handbook of emotions. New York: The Guilford Press 2000; pp. 504-20.

[26] Forgas JP. Introduction: Affect and social cognition. In Forgas JP, Ed. Handbook of affect and social cognition. New Jersey: Lawrence Erlbaum Associates 2001; pp. 1-26.

[27] Leary MR. The sociometer, self-esteem, and the regulation of interpresonal bahavior. In: Baumeister RF, Vohs KD, Eds. Handbook of self-regulation. New York: The Guilford Press 2004; pp. 373-91.

[28] Rothman AJ, Baldwin AS. Self-regulation and behavior change: disentangling behavioral initiation and behavioral maintenance. In: Baumeister RF, Vohs KD, Eds. Handbook of self-regulation. New York: The Guilford Press 2004; pp. 130-50.

[29] Luce, MF. Choosing to avoid: coping with negatively emotionladen consumer decisions. J Consum Res 1989: 24; 409-33.

[30] Parrot WG, Spackman MP. Emotion and memory. In Lewis M, Haviland-Jones JM, Ed. Handbook of emotions. New York: The Guilford Press 2000; pp. 476-90.

[31] Eysenck MW. Psychology: a student's handbook. East Sussex: Psychology Press 2000.

[32] Benet-Martinez V, John, OP. Los cinco grandes across cultures and ethnic groups: Multitrait multimethod analyses of the big five in Spanish and Engish. J Pers Soc Psychol 1998; 75: 729-50.

[33] Goldberg LR. An alternative "description of personality": the bigfive factor structure. J Person Soc Psychol 1990; 59: 1216-29.

[34] Larsen RJ, Buss DM. Personality psychology: domains of knowledge about human nature. New York: McGraw-Hill 2002.

[35] Law KS, Wong CS. The construct and criterion validity of emotional intelligence and its potential utility for management studies. J Appl Psychol 2004; 89(3): 483-96.

[36] Zeidner M, Roberts RD. The science of emotional intelligence current consensus and controversies. Eur Psychol 2008; 13: 64-78.

[37] Ng W, Diener E. Personality differences in emotions: does emotion regulation play a role? J Ind Diff 2009; 30: 100-106.

[38] Gross JJ, John OP. Mapping the domain of expressivity: Multimethod evidence for a hierarchical model. J Person Soc Psychol 1998; 74: 170-91. 
[39] John OP, Gross JJ. Individual differences in emotion regulation. In: Gross JJ, Ed. Handbook of emotion regulation. New York: The Guilford Press 2007; pp. 351-72.

[40] Matthews G, Emo AK. Emotional intelligence, personality, and task-induced stress. J Exp Psychol 2006; 12: 96-107.

[41] Connor-Smith JK. Relations between personality and coping: metaanalysis. J Person Soc Psychol 2007; 93: 1080-107.

[42] Wong KF, Yik M. Understanding the emotional aspects of escalation of commitment: the role of negative affect. J Appl Psychol 2006; 91: 282-97.

[43] Berg J, Dickhaut J. Trust, reciproicty, and social history. Game Econ Behav 1995; 10: 122-42.

[44] McEvily B, Weber RA. Can groups be trusted? An experimental study of trust in collective entities. In: Bachmann R, Zaheer A, Eds. Handbook of trust research. Cheltenham: Edward Elgar Publishing Limited 2006; pp. 52-67.

[45] Fetchenhauer D, Dunning D. Do people trust too much or too little? J Econ Psychol 2009; 30: 263-76.

[46] Watson D, Clark LA. Development and validation of brief measures of postive and negative affect: the PANAS scales. J Person Soc Psychol 1988; 54: 1063-70.

[47] Kramer RM. Trust as situated cognition: an ecological perspective on trust decisions. In: Bachmann R, Zaheer A, Eds. Handbook of trust research. Massachusetts: Edward Elgar Publishing 2006; pp. 68-84.

[48] Holm H, Nystedt P. Trust in surveys and games - A methodological contribution on the influence of money and location. J Econ Psychol 2008; 29: 522-42.

[49] Ben-Ner A, Halldorsson F. Trusting and trustworthiness: what are they, how to measure them, and what affects them. J Econ Psychol 2010; 31: 64-79.

[50] Tamir M, John OP. Implicit theories of emotion: Affective and social outcomes across a major life transition. J Person Soc Psychol 2007; 92: 731-44.

[50] Tamir M, John OP. Implicit theories of emotion: affective and social outcomes across a major life transition. J Person Soc Psychol 2007; 92: 731-44.

[51] Spörrle M, Welpe IM. How to feel rationally: Linking rational emotive behavior therapy with components of emotional intelligence. In: Hartel CEJ, Zerbe WJ, Ashkanasy NM, Eds. Research on emotion in organizations. San Diego: JAI Press 2006; vol. 7, pp. 291-321.

[52] Boss AD, Sims HP. Everyone fails! using emotion regulation and self-leadership for recovery. J Manag Psychol 2008; 23: 135-50.

(C) Lee and Selart; Licensee Bentham Open.

This is an open access article licensed under the terms of the (https://creativecommons.org/licenses/by/4.0/legalcode), which permits unrestricted, noncommercial use, distribution and reproduction in any medium, provided the work is properly cited. 